\title{
Subtoxic levels of hydrogen peroxide induce brain-derived neurotrophic factor expression to protect PC12 cells
}

Yurina Ogura', Kazunori Sato ${ }^{1}$, Ken-Ichi Kawashima ${ }^{1}$, Nanako Kobayashi' ${ }^{2}$ Sei Imura ${ }^{2}$, Kotaro Fujino', Hideo Kawaguchi ${ }^{1,2}$ and Taku Nedachi ${ }^{1,2^{*}}$

\begin{abstract}
Background: Oxidative stress is one of the mechanisms underlying pathogenesis in neurodegenerative diseases such as Alzheimer's disease. Generally, oxidative stress represents cell toxicity; however, we recently found that oxidative stress promotes the expression of growth factor progranulin (PGRN) in HT22 murine hippocampus cells, thereby protecting the HT22 cells. In this study, we attempted to clarify whether a similar system exists in the other neuronal cell model, rat pheochromocytoma (PC12) cells.

Results: After confirming that high concentrations of hydrogen peroxide $\left(\mathrm{H}_{2} \mathrm{O}_{2} ; 100-250 \mu \mathrm{M}\right)$ initiate $\mathrm{PC} 12$ cell death, we analyzed growth factor expressional changes after $\mathrm{H}_{2} \mathrm{O}_{2}$ treatment. We found, intriguingly, that gene expression of brain-derived neurotrophic factor (BDNF), but not $P G R N$ was significantly induced by $\mathrm{H}_{2} \mathrm{O}_{2}$. Although little expression of the high affinity BDNF receptor tropomyosin-related kinase TrkB was observed in PC12 cells, expression of low affinity neurotrophin receptor, p75NTR, was clearly observed. This BDNF signaling appeared to contribute to PC12 cell protection, since PC12 cell death was significantly attenuated by BDNF treatment.
\end{abstract}

Conclusions: Based on our results, we conclude that the induction of BDNF by subtoxic levels of $\mathrm{H}_{2} \mathrm{O}_{2}$ and its signaling may have roles in PC12 cell protection.

Keywords: Oxidative stress, BDNF, PC12 cells, Cell death

\section{Background}

Oxidative stress is generated by increases in reactive oxygen species (ROS) produced in the mitochondria and often has toxic effects on cell functions [1]. In the central nervous system (CNS), numerous reports suggest that oxidative stress is involved in the progression of some neurodegenerative diseases, such as Alzheimer's disease (AD), Parkinson's disease, and amyotrophic lateral sclerosis (ALS) [2-4]. Hence, understanding how oxidative stress enhances neuronal cell toxicity and exploring methods to control oxidative stress in the CNS are extremely important.

Neurotrophins such as nerve growth factors (NGF), brainderived neurotrophic factor (BDNF), and neurotrophin-3

\footnotetext{
* Correspondence: nedachi@toyo.jp

'Department of Life Sciences, Graduate School of Life Sciences, Toyo University, 1-1-1 Izumino, Itakura-machi, Oura-gun, Gunma 374-0193, Japan ${ }^{2}$ Faculty of Life Sciences, Toyo University, 1-1-1 Izumino, Itakura-machi, Oura-gun, Gunma 374-0193, Japan
}

(NT-3), contribute to neuronal cell protection against oxidative stress [5]. Activation of mitogen-activated protein kinase (MAPK) and phosphatidylinositol 3-kinase (PI3K) cascades by these neurotrophic growth factors appears to have a central role in cell protection [6]. These two signaling cascades are generally activated via tropomyosin-related kinase (Trk) receptors that have tyrosine kinase activity (TrkA for NGF, TrkB for BDNF, and TrkC for NT-3, respectively). These neurotrophins have a different type of receptor, p75 neurotrophin receptor (p75NTR), whose role is less clear than that of Trk receptors. p75NTR belongs to the tumor necrosis factor receptor (TNFR) superfamily, and possesses similar ligand-dependent signaling pathways to TNFRs $[7,8]$. Two major pathways activated by p75NTR are well documented: nuclear factor $\kappa B(N F-\kappa B)$ pathway and Jun kinase (JNK) pathway [6]. Evidence suggests that the activation of the NF-kB pathway by p75NTR 
engagement promotes cell survival, whereas activation of JNK pathway promotes apoptosis [6]. These two distinct signaling pathways have completely opposite bio-effects, making the interpretation of physiological function of p75NTR signaling difficult.

The expression of neurotrophins from neuronal cells was regulated by multiple distinct stimulations. Recently, we found that subtoxic levels of oxidative stress significantly promoted the expression of a neurotrophic factor, progranulin $(P G R N)$, in HT22 murine hippocampal cells [9]. Intriguingly, the expressed PGRN appeared to serve as autocrine/paracrine factor that had neuroprotective roles [9]. Based on this previous work, we hypothesized that when a neuronal cell experiences high levels of stress, the cell activates this autocrine/paracrine mechanism to protect itself and other cells. Whether similar autocrine/ paracrine mechanisms, which are activated by subtoxic levels of oxidative stress, exist in other cell types is not well understood. The differentiated rat pheochromocytoma (PC12) cells have neuron-like characteristics [10], and thereby are often used for studying neuroprotection $[11,12]$. Using the PC12 model, we determined whether subtoxic levels of oxidative stress activated observable neurotropic factor-mediated autocrine/paracrine cell protective mechanisms.

\section{Methods}

\section{Materials}

The western blot detection kit (ECL plus or ECL prime detection reagents) was from GE Healthcare Inc. (Rockford, IL, USA). Dulbecco's Modified Eagle Medium (DMEM), penicillin/streptomycin and Trypsin-EDTA were purchased from Nakaraitesque (Kyoto, Japan). Cell culture equipment was from BD Biosciences (San Jose, CA, USA). Calf Serum (CS) and Fetal Bovine Serum (FBS) were obtained from BioWest (Nuaille, France). Immobilon-P was from Millipore Corp. (Bedford, MA, USA). Unless otherwise noted, all chemicals were of the purest grade available from Nakaraitesque, Sigma Chemicals (St. Louis, MO, USA) or Wako Pure Chemical Industries, Ltd. (Osaka, Japan). Because only an established cell line (PC12 cell) was used in this study, the ethics approval was not required.

\section{Cell culture}

An established rat adrenal pheochromocytoma cell line, PC12 cell, was obtained from Dr. Shin-Ichiro Takahashi (The University of Tokyo, Tokyo, Japan). The PC12 cells were maintained in DMEM containing 10\% FBS, $30 \mu \mathrm{g} / \mathrm{ml}$ penicillin, $100 \mu \mathrm{g} / \mathrm{ml}$ streptomycin at $37^{\circ} \mathrm{C}$ under a $5 \%$ $\mathrm{CO}_{2}$ atmosphere. The medium was exchanged every $72 \mathrm{~h}$. For all experiments, cells were grown on 6-well plates (Corning Inc., Corning, NY, USA) at a density of $5 \times 10^{4}$ cells/well in $3 \mathrm{ml}$ of growth medium, or on 96-well plates (Corning Inc.) at a density of $5 \times 10^{3}$ cells/well in $0.2 \mathrm{ml}$ of growth medium. Three days after plating, cells typically reached 50-70\% confluence (Day 0). Differentiation was then induced by switching to DMEM supplemented with $100 \mathrm{ng} / \mathrm{ml} \mathrm{NGF}, 30 \mu \mathrm{g} / \mathrm{ml}$ penicillin, and $100 \mu \mathrm{g} / \mathrm{ml}$ streptomycin.

\section{Measurement of cell death}

PC12 cells were seeded on 96-well plates and differentiated as described previously [13]. The percentage of cell death was evaluated using the lactose dehydrogenase (LDH) plus kit (Roche Diagnostics K.K., Basel, Switzerland) according to the manufacturer's protocol.

\section{Western blotting}

The expression and phosphorylation of each protein were analyzed by western blot analysis as described previously [13]. Briefly, the cells were seeded on 6-well plates at a density of $1 \times 10^{5}$ cells/well, and $24 \mathrm{~h}$ later, the cells were treated with different concentrations of hydrogen peroxide $\left(\mathrm{H}_{2} \mathrm{O}_{2}\right)$ for $30 \mathrm{~min}$. The cell lysates were prepared using lysis buffer (2\% sodium dodecyl sulfate (SDS), 1\% 2mercaptoethanol, 10\% glycerol, $0.0033 \%$ Bromophenol Blue and $50 \mathrm{mM}$ Tris- $\mathrm{Cl}$ [pH 6.8]). These cell lysates were resolved to $12 \%$ SDS-polyacrylamide gel electrophoresis (1:30, bis:acrylamide). Proteins were transferred to a polyvinylidene difluoride (PVDF) membrane (Immobilon-P; Millipore Corp, Bedford, MA, USA), and the membranes were blocked for $30 \mathrm{~min}$ at $3 \%$ bovine serum albumin (BSA) in tris buffered saline (TBS) containing $0.1 \%$ Tween-20. Detection of each protein was achieved with $1 \mathrm{~h}$ incubation with a 1:1000 dilution of primary antibody (anti-phospho Akt (S473), anti-Akt, anti-phospho Erk1/2, anti-Erk1/2, anti-phospho JNK, anti-JNK, anti-phospho p38, anti-p38, anti-IкB antibodies (Cell Signaling Technology, Danvers, MA, USA)). Specific total proteins were visualized after subsequent incubation with a 1:5000 dilution of anti-mouse or rabbit IgG conjugated to horseradish peroxidase and an ECL plus detection procedure (GE Healthcare Inc., Buckinghamshire, UK). At least three independent experiments were performed for each condition.

\section{PCR}

RNA isolation from differentiated PC12 cells was performed using a Blood/Cultured Cell Total RNA mini kit (Favorgen Biotech Corp., Taiwan). The extracted total RNA was subjected to reverse transcriptase reaction using a PrimeScript real-time PCR (RT-PCR) kit (TAKARA, Osaka, Japan). PCR was performed using KAPATaq EXtra HotStart ReadyMix with dye (KAPA Biosystems Inc., Woburn, MA, USA) and the following PCR primers: rat TrkA, 5'-ATG CTC GTC AGG ACT TCC ATC G-3' and 5'-TAG CCA CAG CCA GAA GCT GC-3'; rat TrkB, 5'-AAG TCC TCT ATG AAG ACT GGA CC-3' and 5' -TGC CAA ACT TGG AAT GTC TCG CCA-3'; rat 
TrkC, 5' -CAG CCC AGA GCC TTT GCT AAG-3' and 5'-GGC AAA GGA GAG CCA GAG CCA TT-3'; rat p75NTR, 5' -CGG AAT TCG GAG ACA TGT TCC ACA GGC-3' and 5'-CCT TGG GAT CCA TCG ACC-3'.

\section{Real-time PCR}

PC12 cells were differentiated as described previously, then treated with different concentrations of $\mathrm{H}_{2} \mathrm{O}_{2}(0-250 \mu \mathrm{M})$ for $12 \mathrm{~h}$. Total RNA was isolated from cells using a High Pure RNA Isolation Kit (Roche Diagnostics, Mannheim, Germany) according to the manufacturer's protocol. cDNAs were synthesized from total RNA using ReverTra Ace qPCR RT Master Mix (TOYOBO, Osaka, Japan). Fluorescence RT-PCR analysis was performed using a StepOne instrument (Life Technologies Corporation; Grand Island, NY, USA) and an SYBR Green detection kit according to the manufacture's protocol (Life Technologies or KAPA Biosystems Inc.; Woburn, MA, USA). PCR primers for measuring each gene included the following: rat BDNF, 5'-TCA AGC TGG AAG CCT GAA TGA A-3' and 5'-GCC AGT CAG GTA ACC ACT AAC AC-3'; rat PGRN, 5'-CAC TGT CCT GAT GGC TAC TCT TG-3' and 5'-CTA CCA GGA CAC TGG ACA GCA C-3'; and rat GAPDH, 5'-GGC ACA GTC AAG GCT GAG AAT G-3' and 5'-ATG GTG GTG AAG ACG CCA GTA-3'.

\section{Statistical analysis}

Comparisons among treatment groups were tested using one-way ANOVA with Tukey's post-tests. Differences for which $\mathrm{p}<0.05$ were considered statistically significant.

\section{Results and discussion}

Subtoxic levels of oxidative stress induces BDNF expression Initially, we confirmed whether the treatment of PC12 cells with $\mathrm{H}_{2} \mathrm{O}_{2}$ induced cell death. As shown in Figure 1A, PC12 cell death gradually increased upon $\mathrm{H}_{2} \mathrm{O}_{2}$ treatment, and significant induction of cell death $(\mathrm{p}<0.05)$ was observed when more than $250 \mu \mathrm{M}$ of $\mathrm{H}_{2} \mathrm{O}_{2}$ was applied to cells (Figure 1A). Moreover, as shown in Figure $1 \mathrm{~B}, \mathrm{H}_{2} \mathrm{O}_{2}$ treatment induced phosphorylation of stress-activated MAP kinases, Erk1/2 and p38, in a concentrationdependent manner, although the other MAP kinase, JNK, was not affected. From these data, we concluded that more than $250 \mu \mathrm{M}$ of $\mathrm{H}_{2} \mathrm{O}_{2}$ indeed promoted oxidative stress to PC12 cells.

As described in the background, we recently reported that subtoxic levels of oxidative stress significantly induced expression of a growth factor PGRN in HT22 murine hippocampal cells, thereby contributing to cell protection [9]. However, gene expression levels of BDNF and IGF-1 were decreased by oxidative stress [9]. These results indicate that when the cells experienced subtoxic levels of oxidative stress, they activated specific intracellular machinery to promote specific growth factors. To investigate whether the expression of growth factors are similarly controlled in PC12 cells, we measured the gene expression of PGRN, BDNF, NT3, and IGF1 after $\mathrm{H}_{2} \mathrm{O}_{2}$ treatment. Of these growth factors, only $B D N F$ gene expression was induced in an $\mathrm{H}_{2} \mathrm{O}_{2}$ concentration-dependent manner (Figure 2A). Consistent with this result, Wang and colleagues report that BDNF secretion from differentiated PC12 cells was induced by hypoxic stimuli that were abolished by $\mathrm{N}$-acetyl-l-cysteine, which is a scavenger of ROS [14]. Although the gene expression of $P G R N$ was clearly observed in $\mathrm{PC} 12$ cells, its expression levels were not altered by $\mathrm{H}_{2} \mathrm{O}_{2}$ administration (Figure 2B). In addition, little gene expression of NT3 and IGF1 was observed (data not shown). Together, these results demonstrate that subtoxic levels of oxidative stress specifically promote $B D N F$ expression in PC12 cells. Moreover, compared to similar experiments using HT22 cells that we previously reported [9], the oxidative stress-dependent regulation of growth factors appeared to be varied among neuronal cell types.

\section{BDNF signals through p75NTR in PC12 cells}

Based on our hypothesis that BDNF induced by $\mathrm{H}_{2} \mathrm{O}_{2}$ may function in an autocrine/paracrine manner, we explored how PC12 cells responded against BDNF. Before evaluating the effects of BDNF on cellular functions, we analyzed whether BDNF receptor was expressed in PC12 cells, since it has been reported that high affinity BDNF receptor, TrkB, is not expressed in PC12 cells [15]. As shown in Figure 3A, we also confirmed that detectable levels of TrkB was not observed. On the contrary, TrkA, TrkC, and low affinity neurotrophin receptor p75NTR were expressed in PC12 cells (Figure 3A). BDNF-p75NTR signaling has been well studied and is especially characterized by prominent activation of NFKB signaling [16]. To test if BDNF treatment affects Trk signaling, we also analyzed Erk1/2 and Akt phosphorylation that are activated by the neurotrophin-Trk dependent signaling pathway. The amount of IкB, which inhibits NFKB nuclear translocation, was not changed by BDNF treatment (Figure 3B). The amounts and phosphorylation of NFKB were also not affected by BDNF (data not shown). In terms of Trk-dependent signaling, changes in Erk1/2 and GSK3 $\beta$ phosphorylation were not observed, but Akt phosphorylation was significantly decreased by BDNF treatment (Figure 3B-E). It was reported that pro-NGF induces expression of phosphatase and tensin homolog deleted on chromosome 10 (PTEN), a negative regulator for PI3K signaling, and thereby abolishes Akt activation in brain neurons [17]. However, our present results revealed that BDNF has an ability to dephosphorylate Akt acutely, within $30 \mathrm{~min}$. Overall, our present data suggest that BDNF inactivated Akt perhaps via p75NTR, although little TrkB was expressed in PC12 cells. 


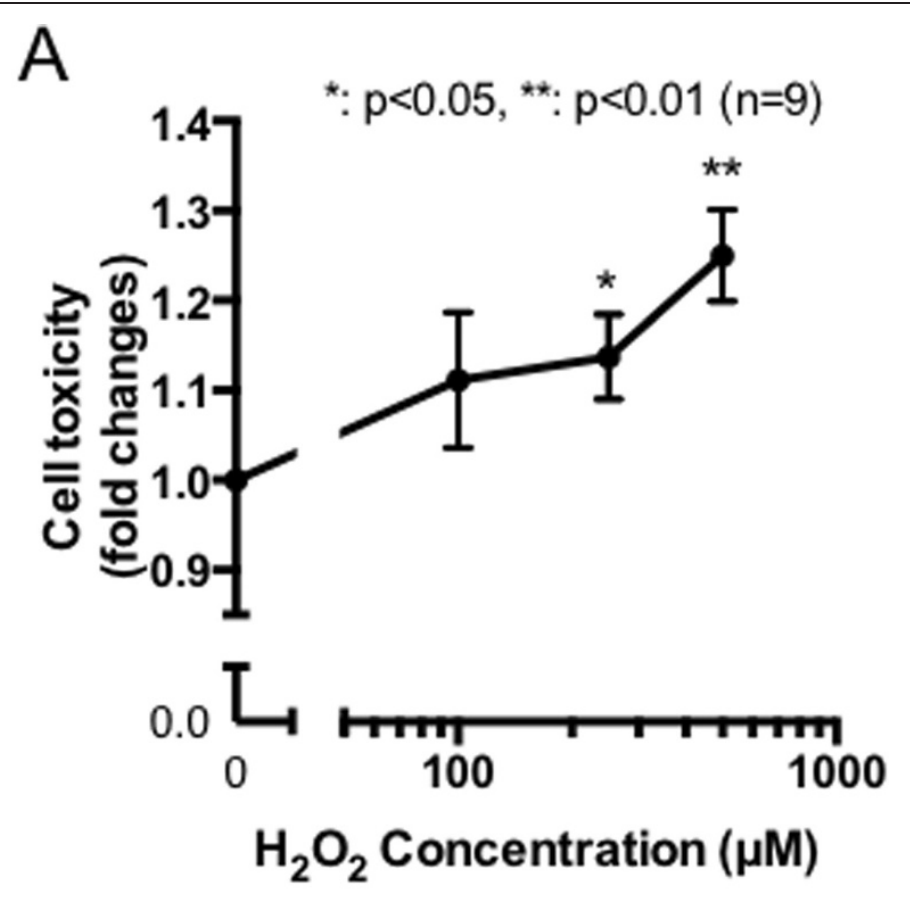

B

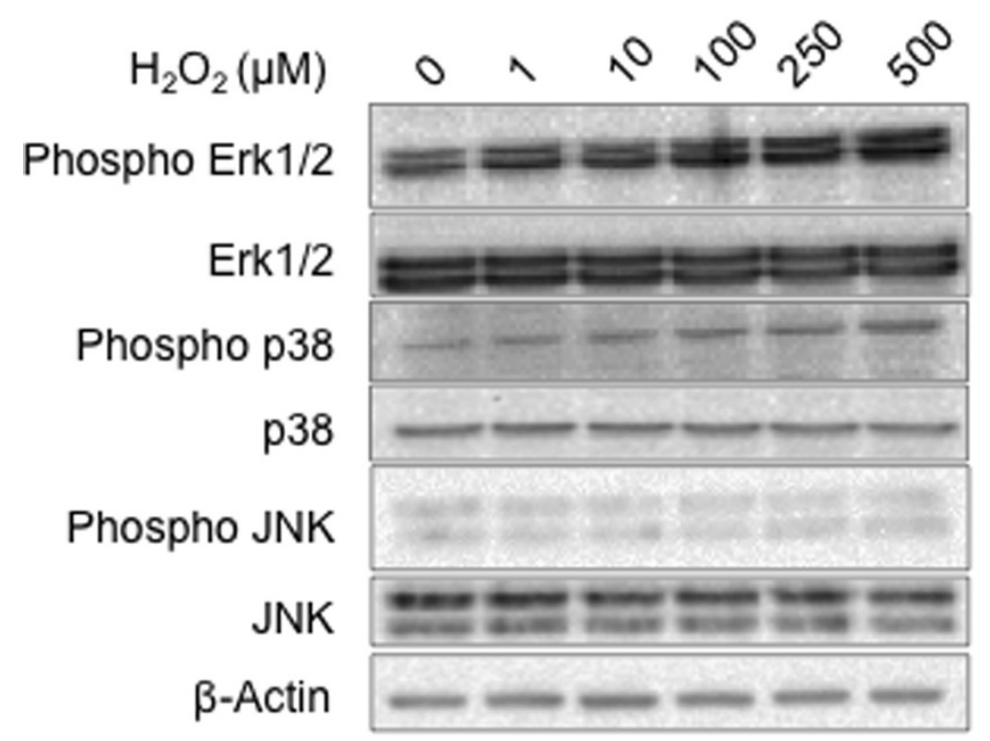

Figure 1 BDNF expression is induced by subtoxic levels of oxidative stress in PC12 cells. (A) Differentiated PC12 cells were stimulated with the indicated concentrations of $\mathrm{H}_{2} \mathrm{O}_{2}$ for $15 \mathrm{~h}$. Cell toxicity was measured by LDH assay. Data shown represent mean \pm SEM, tested using a one-way ANOVA with Tukey's post-test (**p $<0.01, n=9$ ). (B) Differentiated $\mathrm{PC} 12$ cells were stimulated with the indicated concentration of $\mathrm{H}_{2} \mathrm{O}_{2}$ for 30 min. Total and phosphorylated proteins were evaluated by western blotting analysis. Three independent experiments were performed and representative data are shown.

BDNF treatments protect PC12 cells

BDNF treatment protects against various insults [18-20]; however, if these protections occur in cells that lack TrkB receptors, such as PC12 cells, is not well studied. To determine if BDNF protects PC12 cells in the absence of TrkB receptors, PC12 cells were treated with
BDNF for $24 \mathrm{~h}$ and cell viability was evaluated by measuring released LDH (described in Methods). As shown in Figure 4A, BDNF treatment slightly but significantly ameliorated PC12 cell survival rate. Currently, we have not identified which signaling pathways mediate cell protective effects dependent on BDNF. Several studies 


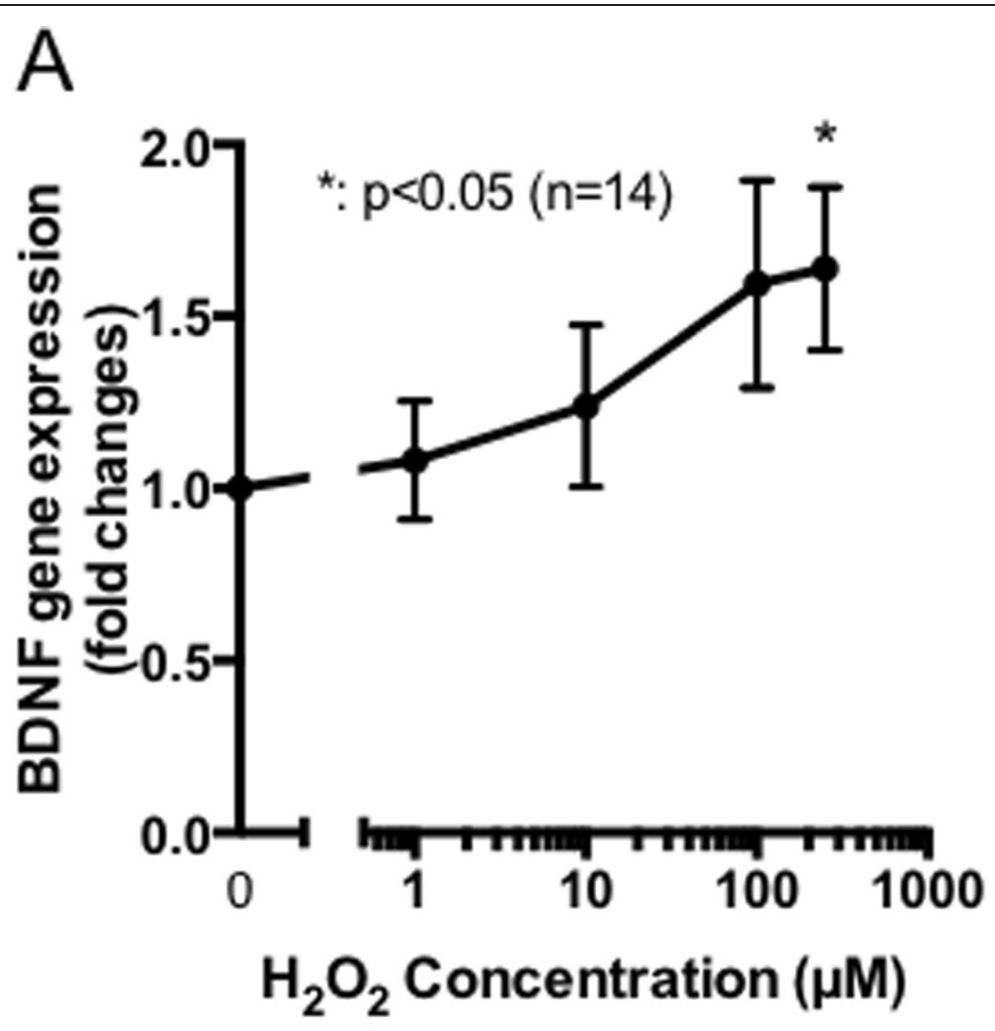

B

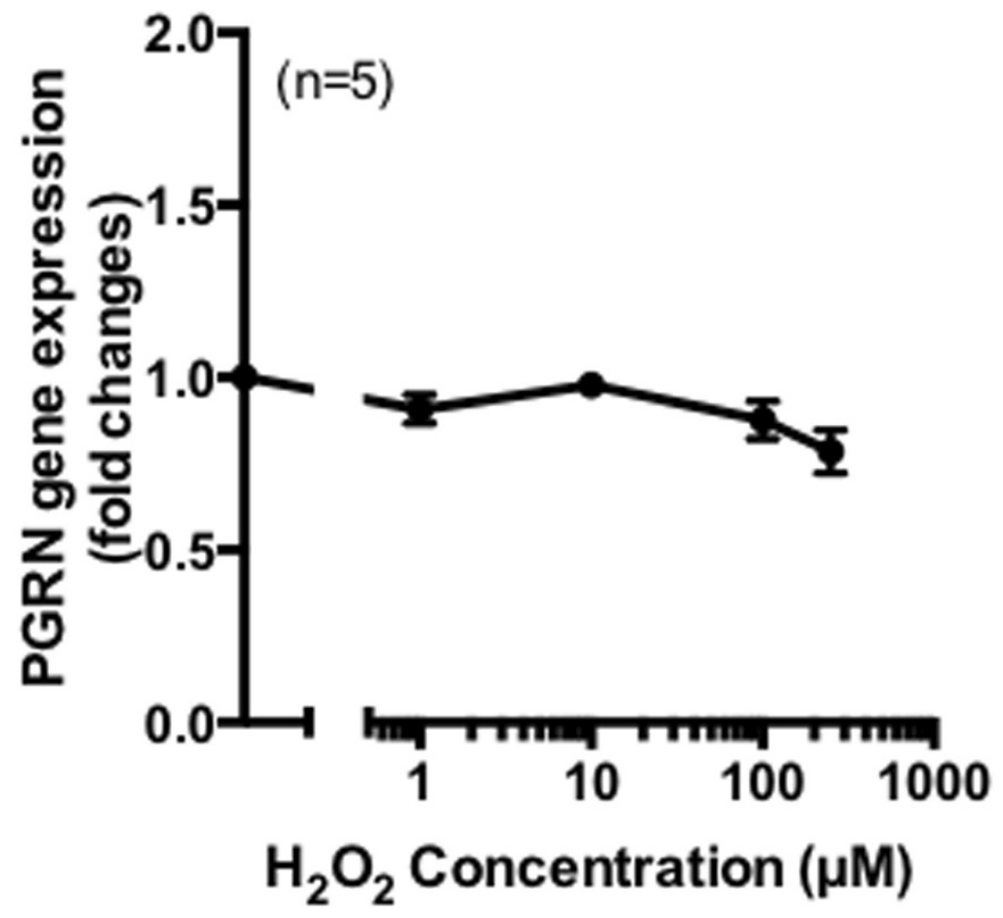

Figure 2 Subtoxic levels of oxidative stress promote BDNF induction. (A, B) Differentiated PC12 cells were stimulated with indicated concentrations of $\mathrm{H}_{2} \mathrm{O}_{2}$ for $15 \mathrm{~h}$. Total RNA was then extracted from the cells and the gene expression of BDNF (A) or PGRN (B) was evaluated by quantitative PCR analysis. Data shown represent mean \pm SEM, tested using one-way ANOVA with Tukey's post-test $\left({ }^{*} \mathrm{p}<0.05, \mathrm{n}=5-14\right.$ ). 
A

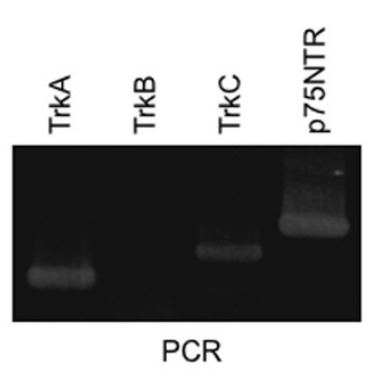

B

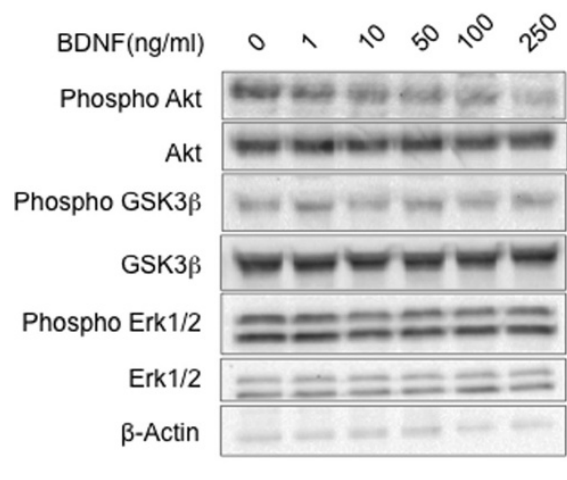

C

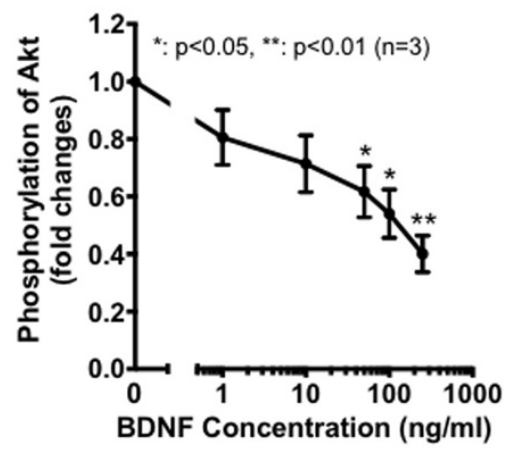

D
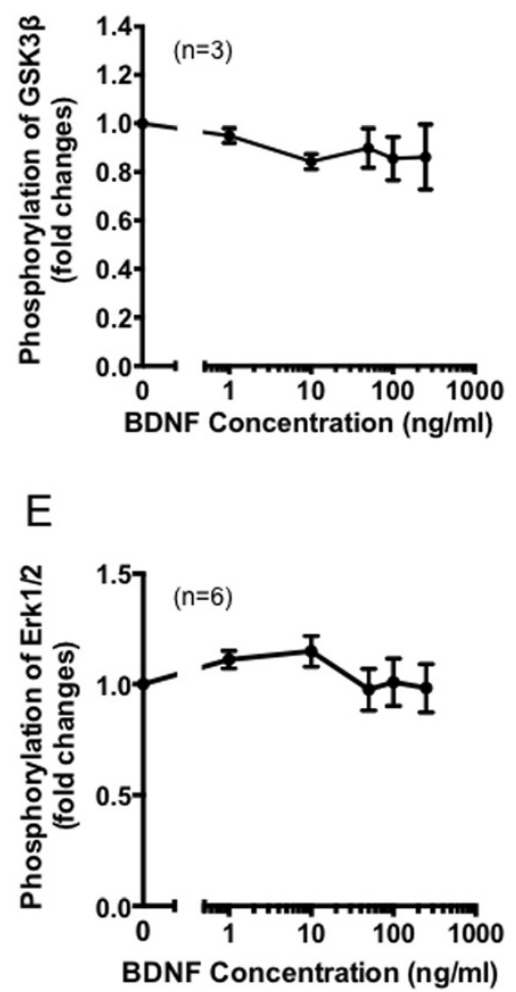

Figure 3 BDNF signaling in PC12 cells. (A) Total RNA was extracted from differentiated PC12 cells. The gene expression of each neurotrophin receptors was evaluated by RT-PCR analysis. (B) Differentiated PC12 cells were treated with the indicated amounts of BDNF for 30 min. Total and phosphorylated proteins were evaluated by western blotting analysis. Three independent experiments were performed and representative data are shown. (C, D, E) Densitometric analysis of (B). Data shown represent mean \pm SEM, tested using one-way ANOVA with Tukey's post-test ( ${ }^{*} \mathrm{p}<0.05$, $\left.{ }^{* *} p<0.01, n=3\right)$.

suggest that p75NTR could promote cell survival by enhancing NGF signaling pathways [21-23]; however, we could not confirm that major NGF signaling pathways, the Erk1/2 and PI3K/Akt cascades, were enhanced by BDNF treatment. Rather, Akt phosphorylation was significantly decreased by the BDNF treatment (Figure 3B, 3C). Pharmacological inhibition of the PI3K/Akt pathway by LY294002 enhanced PC12 cell death (Figure 4B), indicating that BDNF-dependent Akt inactivation might contribute to induction of cell death. It should be noted that the oxidative stress-dependent induction of $B D N F$ gene might also result in enhancement of pro-BDNF production. Although whether pro-BDNF has a physiological function has been controversial $[24,25]$, recent reports suggest that pro-BDNF preferentially binds to p75NTR, and exerts pro-apoptotic effects [26]. However, intriguingly, exogenous pro-BDNF treatment also tended to reduce PC12 cell death (Figure 4C). Thus, although further experiments are required to measure the concentration of mature BDNF and pro-BDNF in the vicinity of cells, the induction of 


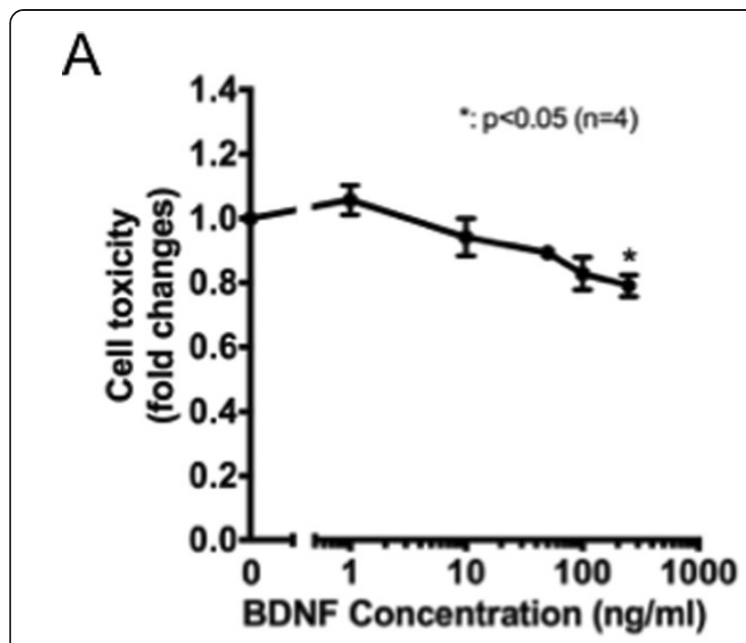

B
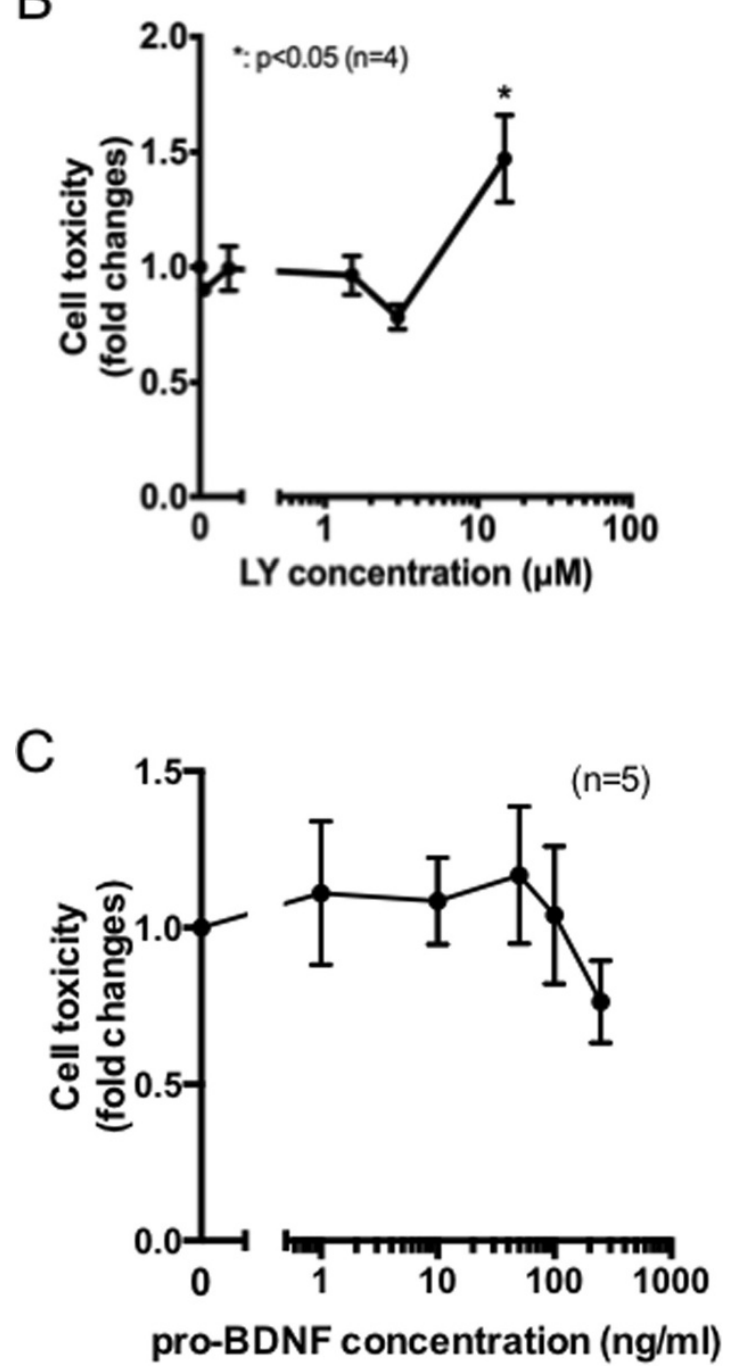

Figure 4 BDNF protects PC12 cells from death. (A) Differentiated PC12 cells were treated with the indicated amounts of BDNF for $15 \mathrm{~h}$, and cell toxicity was measured by LDH assay. Data shown represent mean \pm SEM, tested using a one-way ANOVA with Tukey's post-tests ( $\left.{ }^{*} p<0.05, n=4\right)$. (B) Differentiated PC12 cells were treated with the indicated amounts of the PI3K inhibitor LY294002 for 15 h, and cell toxicity was measured by LDH assay. Data shown represent mean \pm SEM, tested using one-way ANOVA with Tukey's post-test ( $\left.{ }^{*} p<0.05, n=4\right)$. (C) Differentiated PC12 cells were treated with the indicated amounts of pro-BDNF for $15 \mathrm{~h}$, and cell toxicity was measured by LDH assay. Data shown represent mean \pm SEM.

BDNF gene by $\mathrm{H}_{2} \mathrm{O}_{2}$ treatment appears to be beneficial for PC12 cells.

Overall, our results suggest that subtoxic levels of oxidative stress promote $B D N F$ gene expression, and possibly exert a cell protective mechanism (Figure 5). Consistent with our present observations, several recent studies suggest that ROS accumulation could exert beneficial effects on adaptation against stress and survival of cells $[27,28]$. We found that although the BDNF-dependent signaling pathway possesses cell protective functions, it perhaps inactivates PI3K/Akt pathway that appeared to be a negative factor for cell survival. Our laboratory is now exploring the other signaling pathway that is activated by BDNF and is crucial for cell protection. An intriguing observation from the present study is that oxidative stress and BDNF potentially activate both cell death and cell survival promoting mechanisms. The balance between these two opposing systems may directly influence the determination of cellular fates.

\section{Conclusions}

Subtoxic levels of oxidative stress induce BDNF gene expression that potentially exerts a cell protective mechanism.

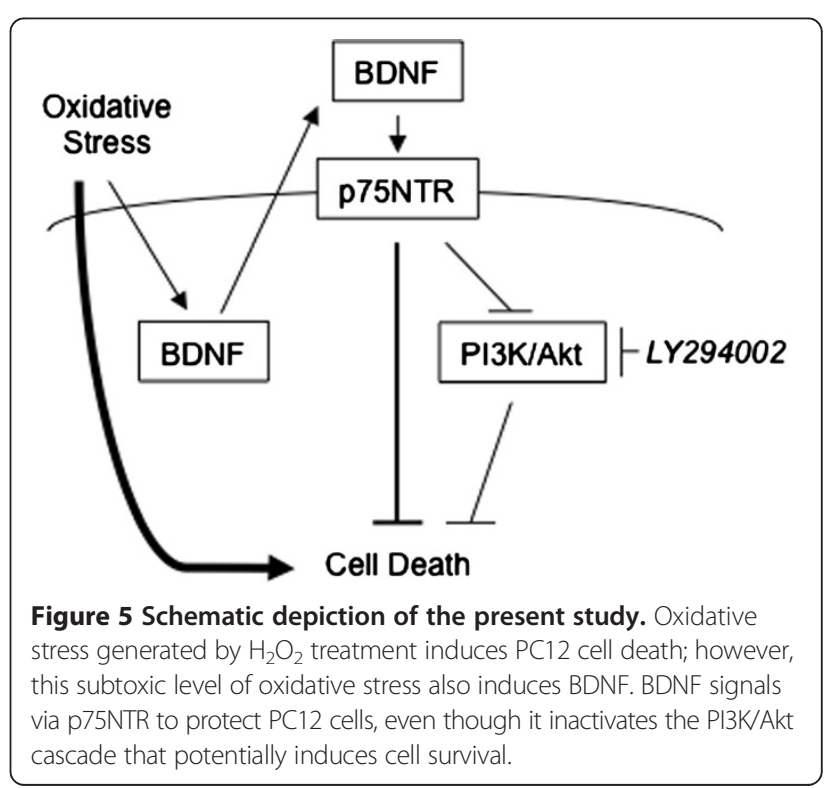




\section{Abbreviations}

BSA: Bovine serum albumin; DMEM: Dulbecco's modified Eagle's medium; LDH: Lactate dehydrogenase; NGF: Nerve growth factor; PCR: Polymerase chain reaction; PBS: Phosphate-buffered saline; TBS: Tris-buffered saline.

\section{Competing interests}

The authors declare that they have no competing interests.

\section{Authors' contributions}

$\mathrm{YO}, \mathrm{HK}$ and TN designed the experiments. YO, KK, KS, NK, SI and KF performed the experiments. YO and TN wrote the paper. All authors read and approved the final manuscript.

\section{Acknowledgements}

We are deeply grateful to Dr. Shin-Ichiro Takahashi for PC12 cells. We also appreciate Dr. Masugi Nishihara (The University of Tokyo) and Dr. Jerome Lamartine (Université Claude Bernard Lyon 1, Lyon, France) for many constructive comments. This work was supported by Grants-in-Aid for Scientific Research (S) 23228004 and (C) 24580147 from the Japan Society for the Promotion of Science.

Received: 8 July 2014 Accepted: 18 November 2014

Published: 25 November 2014

\section{References}

1. Dai DF, Chiao YA, Marcinek DJ, Szeto HH, Rabinovitch PS: Mitochondrial oxidative stress in aging and healthspan. Longev Healthspan 2014, 3:6.

2. Andersen JK: Oxidative stress in neurodegeneration: cause or consequence? Nat Med 2004, 10(Suppl):S18-S25.

3. Shukla V, Mishra SK, Pant HC: Oxidative stress in neurodegeneration. Adv Pharmacol Sci 2011, 2011:572-634.

4. Zarkovic K: 4-hydroxynonenal and neurodegenerative diseases. Mol Aspects Med 2004, 24:293-303.

5. Ichim G, Tauszig-Delamasure S, Mehlen P: Neurotrophins and cell death. Exp Cell Res 2012, 318:1221-1228.

6. Reichardt LF: Neurotrophin-regulated signalling pathways. Philos Trans $R$ Soc Lond B Biol Sci 2006, 361:1545-1564.

7. Zeng F, Lu JJ, Zhou XF, Wang YJ: Roles of p75NTR in the pathogenesis of Alzheimer's disease: a novel therapeutic target. Biochem Pharmacol 2011, 82:2500-1509

8. Friedman WJ, Greene LA: Neurotrophin signaling via Trks and p75. Exp Cell Res 1999, 253:131-142.

9. Sato K, Yamanaka Y, Ishii M, Ishibashi K, Ogura Y, Ohtani-Kaneko R, Nishihara $\mathrm{M}$, Nedachi T: Dual cell protective mechanisms activated by differing levels of oxidative stress in HT22 murine hippocampal cells. Biosci Biotech Biochem 2014, 78(9):1495-1503.

10. Gunning PW, Landreth GE, Layer P, Ignatius M, Shooter EM: Nerve growth factor-induced differentiation of $\mathrm{PC} 12$ cells: evaluation of changes in RNA and DNA metabolism. J Neurosci 1981, 1:368-379.

11. Tabakman R, Lazarovici $P$, Kohen R: Neuroprotective effects of carnosine and homocarnosine on pheochromocytoma PC12 cells exposed to ischemia. J Neurosci Res 2002, 68:463-469.

12. Li G, Ma R, Huang C, Tang Q, Fu Q, Liu H, Hu B, Xiang J: Protective effect of erythropoietin on beta-amyloid-induced $\mathrm{PC} 12$ cell death through antioxidant mechanisms. Neurosci Lett 2008, 442:143-147.

13. Fujino K, Ogura Y, Sato K, Nedachi T: Potential neuroprotective effects of SIRT1 induced by glucose deprivation in PC12 cells. Neurosci Lett 2013, 557:148-153.

14. Wang H, Yuan G, Prebhakar NR, Boswell M, Katz DM: Secretion of brain-derived neurotrophic factor from $\mathrm{PC} 12$ cells in response to oxidative stress requires autocrine dopamine signaling. J Neurochem 2006, 96:694-705.

15. Iwasaki Y, Ishikawa M, Okada N, Koizumi S: Induction of a distinct morphology and signal transduction in TrkB/PC12 cells by nerve growth factor and brain-derived neurotrophic factor. J Neurochem 1997, 68:927-934.

16. Constantini C, Rossi F, Formaggio E, Bernardoni R, Cecconi D, Della-Bianca V: Characterization of the signaling pathway downstream p75 neurotrophin receptor involved in beta-amyloid peptide-dependent cell death. $J \mathrm{Mol}$ Neurosci 2005, 25:141-156.

17. Song W, Volosin M, Cragnolini AB, Hempstead BL, Friedman WJ: ProNGF induces PTEN via p75NTR to suppress Trk-mediated survival signaling in brain neurons. J Neurosci 2010, 30:15608-15615.
18. Shimohama S, Tamura Y, Akaike A, Tsukahara T, Ohara O, Watanabe S, Kimura J: Brain-derived neurotrophic factor pretreatment exerts a partially protective effect against glutamate-induced neurotoxicity in cultured rat cortical neurons. Neurosci Lett 1993, 164:55-58.

19. Cheng B, Mattson MP: NT-3 and BDNF protect CNS neurons against metabolic/excitotoxic insults. Brain Res 1994, 640:56-67.

20. Jian Z, Nonaka I, Hattori S, Nakamura S: Activation of Ras and protection from apoptotic cell death by BDNF in PC12 cells expressing TrkB. Cell Signal 1996, 8:365-370.

21. Lad SP, Peterson DA, Bradshow RA, Neet KE: Individual and combined effects of TrkA and p75NTR nerve growth factor receptors: a role for the high affinity receptor site. J Biol Chem 2003, 278:24808-24817.

22. Culmsee C, Gerling N, Lehmann M, Nikolova-Karakashian M, Prehn JH, Mattson MP, Krieglstein J: Nerve growth factor survival signaling in cultured hippocampal neurons is mediated through TrkA and requires the common neurotrophin receptor P75. Neurosci 2002, 115(4):1089-1108.

23. Zaccaro MC, Ivanisevic L, Perez P, Meakin SO, Saragovi HU: p75 Co-receptors regulate ligand-dependent and ligand-independent Trk receptor activation, in part by altering Trk docking subdomains. J Biol Chem 2001, 276(33):31023-31029.

24. Pang PT, Teng HK, Zaitsev E, Woo NT, Sakata K, Zhen S, Teng KK, Yung WH, Hempstead BL, Lu B: Cleavage of proBDNF by tPA/plasmin is essential for long-term hippocampal plasticity. Science 2004, 306:487-491.

25. Matsumoto T, Rauskolb S, Polack M, Klose J, Kolbeck R, Korte M, Barde YA: Biosynthesis and processing of endogenous BDNF: CNS neurons store and secrete BDNF, not pro-BDNF. Nat Neurosci 2008, 11(2):131-133.

26. Teng HK, Teng KK, Lee R, Wright S, Tevar S, Almeida RD, Kermani P, Torkin $R$, Chen ZY, Lee FS, Kraemer RT, Nykjaer A, Hempstead BL: ProBDNF induces neuronal apoptosis via activation of a receptor complex of p75NTR and sortilin. J Neurosci 2005, 25(22):5455-5463.

27. Yan $\sqcup$ : Protein redox modification as a cellular defense mechanism against tissue ischemic injury. Oxid Med Cell Longev 2014, 2014:Article ID 343154.

28. Groeger G, Quiney C, Cotter TG: Hydrogen peroxide as a cell-survival signaling molecule. Antioxidants and Redox Signaling 2009, 11(11):2655-2671.

doi:10.1186/1756-0500-7-840

Cite this article as: Ogura et al:: Subtoxic levels of hydrogen peroxide induce brain-derived neurotrophic factor expression to protect PC12 cells. BMC Research Notes 2014 7:840,

\section{Submit your next manuscript to BioMed Central and take full advantage of:}

- Convenient online submission

- Thorough peer review

- No space constraints or color figure charges

- Immediate publication on acceptance

- Inclusion in PubMed, CAS, Scopus and Google Scholar

- Research which is freely available for redistribution 